\title{
The Effect of Completion Risk and Project Profitability on the Investment Decisions of the Private Sector in PPP Projects
}

\author{
Linna Geng $\mathbb{D}^{1},{ }^{1}$ Hezhong Zheng $\mathbb{D}^{2}$, and Yao Sun $\mathbb{D}^{3}$ \\ ${ }^{1}$ Department of Infrastructure Engineering, University of Melbourne, Melbourne 3010, Australia \\ ${ }^{2}$ Weifang Engineering Vocational College, Weifang 262737, China \\ ${ }^{3}$ School of Economics, Nankai University, Tianjin 300071, China \\ Correspondence should be addressed to Yao Sun; 1095355328@qq.com
}

Received 5 July 2021; Revised 6 October 2021; Accepted 23 November 2021; Published 2 February 2022

Academic Editor: Serdar Ulubeyli

Copyright ( $\odot 2022$ Linna Geng et al. This is an open access article distributed under the Creative Commons Attribution License, which permits unrestricted use, distribution, and reproduction in any medium, provided the original work is properly cited.

Public-private partnership (PPP) is becoming increasingly popular around the world for the development of infrastructure. However, it is vital that the private sector knows how to make its investment decisions, especially when it bears the burden of completion risk, and the cash flow of PPP projects is hard to predict. In previous studies, completion risk and project profitability have been recognized as critical factors that influence the involvement of the private sector in PPP projects. This study further investigates how these two factors affect private sector investment decisions, including its involvement, withdrawal, and capital structure decisions. First, a continuous real option method is built to explore the investment boundary and default boundary of the private sector. The results show that an increase in completion risk does not necessarily increase the investment boundary; rather, the relationship between them depends on the degree of private sector risk tolerance. The results also indicate that the investment boundary decreases with the expected rate of return and increases with the tax rate, risk-free rate, and volatility of cash flow. The default boundary decreases with the expected rate of return and volatility of cash flow and increases with the risk-free rate. Second, by comparing two different financial arrangements, the results suggest that using debt capital can help lower the private sector's investment boundary. Third, the results reveal the optimal debt level of private sector investment in PPP projects by showing that the optimal debt level increases with the tax rate and decreases with the default loss rate. These results can provide some managerial insights for the private sector as it makes decisions on PPP project investments. They can also provide some policy insights for governments to better promote private sector investment in PPP projects.

\section{Introduction}

With the financial burden of governments growing around the world, the public-private partnership (PPP) model is becoming increasingly popular in infrastructure development $[1,2]$. In PPP projects, the private sectors are mainly responsible for financing, building, and operation of projects $[3,4]$. This approach can largely decrease the financial burden on the government while also gaining more advanced managerial and technical experience from the private sectors in infrastructure development [5]. To make use of the advantages of the PPP model, since 2014, the Chinese government has drafted several policy papers to encourage private sectors to invest in infrastructure development. However, although private sectors have demonstrated their interest in PPP projects, they have hesitated to invest in them. The number of PPP projects that were implemented in 2016 only represents 31.6 percent of the total PPP projects proposed. To better direct the private investor involvement in PPP projects, it is imperative to investigate how different factors affect the investment decision of the private investor.

\section{Literature Review}

Several researchers have identified the critical factors that impede the investment of private investors in PPP projects. In this regard, Ke et al. [6] explored the critical factors that affect the investment decision of the private investor in urban railway PPP projects, in which project profitability, risk sharing, government commitment, public acceptance, 
and regulation were identified as critical factors. Ameyaw et al. [7] identified 8 critical factors that impede the private investor to invest in water-supply PPP projects in developing countries, and project profitability and risk sharing are on the list. From a broad point of view, Osei-Kyei and Chan [8] investigated critical factors that impact the private investor's investment in developing countries.

Researchers have also studied many of the issues that undermine the value for money of PPP projects in practice, e.g., numerous project renegotiations, improper government guarantees, and early termination $[9,10]$. These issues are partially caused by the unreasonable risk allocation between the private sector and government [11-14]. Based on the principle that risk should be allocated to the party that can best handle it, many studies have been conducted to investigate how to allocate different project risks reasonably between the private sector and government $[12,13,15,16]$. Among them, the completion risk is a critical factor that influences the success of PPP projects [17]. However, existing opinions on how this risk should be allocated between the private sector and government are divergent. After analyzing the case of the Channel Tunnel project, Park and Chang [18] argued that the completion risk of PPP projects should be shared between the private sector and government. However, other studies have argued that the completion risk of PPP projects should be allocated to the private sector, which is believed to be the party that can handle this risk best [16]. Since in most cases the completion risk of PPP projects is allocated to the private sector [16], this study follows the argument that the private sector should undertake the completion risk of PPP projects.

Although previous studies identified completion risk and project profitability as critical factors that influence the involvement of the private sector in PPP projects $[16,18,19]$, less research has been undertaken to investigate how these factors affect private sector investment decisions, such as when the private sector should become involved in or withdraw from a project and how the private sector should arrange its capital structure. Since the cash flow of PPP projects is hard to predict and the private sector must shoulder the burden of the completion risk, it is vital for the private sector to know how to make its investment decisions according to different completion risk and project profitability situations. Set against this contextual backdrop, this paper aims to investigate how completion risk and project profitability affect the investment decisions of the private sector in PPP projects. To achieve its objective, this study first builds up a continuous real option model. In comparison to the traditional NPV (net present value) analysis method, the real option method can better capture the uncertainty in PPP projects $[20,21]$. Then, this study determines the private sector's investment boundary and default boundary based on the potential cash flow of the PPP project and analyzes how these two boundaries change according to completion risk and project profitability-related factors. Furthermore, to manifest the relationship between the investment boundary and the capital structure of the private sector, two financial arrangements that use single equity capital and both equity and debt capital are compared.
When the private sector uses both equity and debt capital, determining the proper capital structure of a PPP project is important since it constrains the ability of the private sector to go ahead with the project [22]. Schaufelberger and Wipadapisut [23] suggested that the private sector should use as much debt capital as possible, providing it meets the requirements of the granting authority. However, Dias and Ioannou [22] found that the optimal debt ratio of a PPP project should not exceed its debt capacity; otherwise, the project's value would be reduced. Bakatjan et al. [24] built a linear programming model to analyze the optimal capital structure of build-operate-transfer power plants in Turkey by taking the debt service cover ratio requirement of banks as constraints and maximizing the internal rate of return of the private sector. Zhang [25] put forward a research framework that can determine the optimal capital structure of the PPP project from four dimensions. Yun et al. [26] proposed an optimal capital structure model that can optimize the debt service cover ratio and the internal rate of return simultaneously. Chen and Liou [27] argued that the optimal capital structure is the result of bargaining between the project company and the bank; they built a bargaining model and found that the greater the project company's bargaining power, the higher the optimal debt level of the project.

Although these studies can provide some useful insights into how to organize the capital structure of a PPP project, since their calculating processes were usually based on the traditional NPV analysis method, it is hard for them to analyze how different uncertainties (e.g., the completion risk and volatility of cash flow) in PPP projects influence the optimal capital structure. To fill this gap, this study derives the optimal debt level of PPP projects and explores how it changes according to completion risk and project profitability-related factors. Some managerial insights will be proposed to help the private sector to organize its capital structure when it encounters these uncertainties.

This paper is organized as follows. A continuous option model is built in Section 2.1. Two financial arrangements that use single equity capital and both equity and debt capital are analyzed in Sections 2.2 and 2.3. The optimal capital structure of PPP projects is derived in Section 2.4. Section 2.5 then details the numerical analyses conducted to verify the above results. Based on the preceding section's analyses, Section 2.6 provides some managerial implications. Finally, the study's conclusion and limitations are detailed in Section 3.

2.1. Modeling. In a PPP project, there are two distinct phases: the construction phase and the operating phase. In the construction phase, suppose the construction cost is $I$. Since some factors (e.g., unforeseen underground conditions, a change in the law, war, etc.) may disrupt the project's construction, the project may not be completed successfully. Suppose this completion risk will happen with the probability of $\rho$, and once this completion risk occurs, the project will have no residual value. This assumption is acceptable since the PPP project has the characteristic of asset 
specificity in the construction period [28]; once the project can no longer be completed, it is hard for the assets to be redeployed to an alternative use. During the operating phase, suppose the project can generate cash flow $X \mathrm{~d} t$ within the time interval $\mathrm{d} t$. Moreover, suppose the distribution of $X$ follows a geometric Brownian motion, namely, $X$ satisfies $\mathrm{d} X=\mu X \mathrm{~d} t+\sigma X \mathrm{~d} Z^{\mathrm{Q}} . \mu$ represents the expected rate of return of the project and satisfies the condition that $\mu<r$ to make sure the model is convergent [29-32]; $r$ represents the risk-free rate; $\sigma$ represents the volatility rate of $X$; and $d Z^{\mathrm{Q}}$ represents the incremental of the geometric Brownian motion under the risk-neutral measure. Suppose the operation cost is $f \mathrm{~d} t$ within the time interval $\mathrm{d} t$, and the tax rate is $\tau$. Table 1 summarizes the key parameters adopted in this paper.

2.2. Benchmark: Financing Only by Equity Capital. The private sector needs to raise capital for the construction of a PPP project. In this section, suppose the private sector only uses its own capital to invest in the project. Since the cash flow of the project is uncertain, the private sector will invest only when the expected value of the project's cash flow is greater than a certain value which is defined as the investment boundary. Suppose this cash flow boundary value is $X_{I}$; when $X>X_{I}$, the private sector will invest. Otherwise, the private sector will just wait until the condition $X>X_{I}$ is satisfied. Once the project begins operation, the private sector has the option to abandon the project if the cash flow of the project deteriorates. There is a cash flow boundary $X_{B}$; when $X<X_{B}$, the private sector will abandon the project, after which there is no residual value for the project.

2.2.1. The Operation Period. During the operation period, the instant net cash flow after tax is $(1-\tau)(X-f)$. Suppose the project value in the operation period is $V_{O}(X)$. It can be derived that $V_{O}(X)$ satisfies the following Bellman equation:

$$
r V_{O}(X) \mathrm{d} t=(1-\tau)(X-f) \mathrm{d} t+E\left(\mathrm{~d} V_{O}(X)\right) .
$$

According to Ito's lemma, equation (1) can be translated into the following differential equation (DE).

$r V_{O}(X)=(1-\tau)(X-f)+\mu X \frac{\partial V_{O}(X)}{\partial X}+\frac{1}{2} \sigma^{2} X^{2} \frac{\partial^{2} V_{O}(X)}{\partial X^{2}}$.

The solution of this DE will be

$$
V_{O}(X)=\frac{1-\tau}{r-\mu} X-\frac{1-\tau}{r} f+A_{1} X^{\beta_{1}}+A_{2} X^{\beta_{2}} .
$$

In this solution, $\beta_{1}$ and $\beta_{2}$ are the roots of the quadratic equation $\sigma^{2} / 2\left(x^{2}-x\right)+\mu x-r=0$ and they satisfy that $\beta_{1}>0, \beta_{2}<0$. When the value of $X$ tends to infinity $(X \longrightarrow+\infty)$, there is no possibility for the project to run into distress, so it must satisfy that $A_{1}=0$. Besides, since the value of the project will drop to 0 after being abandoned, the project value in the operation period should satisfy two other conditions (value matching condition and smooth passing condition) as follows:

$$
\begin{aligned}
V_{O}\left(X_{B}\right) & =0 \text { (value matching condition), } \\
\left.\frac{\partial V_{O}(X)}{\partial X}\right|_{X=X_{B}} & =0 \text { (smooth passing condition), }
\end{aligned}
$$

where $X_{B}$ represents the boundary value of the cash flow that triggers the private sector to abandon the project, which is defined as the default boundary. The value matching condition (4) means that when the private sector abandons the project, the residual value of the project equals 0 . The smooth passing condition means that the incremental value of the project at the boundary equals 0 ; this condition implies that the private sector will choose an optimal abandonment boundary to maximize the project's total value.

Combining equations (3)-(5), the analytic expression of $V_{O}(X)$ and $X_{B}$ can be derived as follows:

$$
\begin{aligned}
V_{O}(X) & =\frac{1-\tau}{r-\mu} X-\frac{1-\tau}{r} f-\left(\frac{1-\tau}{r-\mu} X_{B}-\frac{1-\tau}{r} f\right)\left(\frac{X}{X_{B}}\right)^{\beta_{2}}, \\
X_{B} & =\frac{r-\mu}{r} \frac{\beta_{2}}{\beta_{2}-1} f .
\end{aligned}
$$

Thereinto, $\beta_{2}=(1 / 2)-\left(\mu / \sigma^{2}\right)-\sqrt{\left((1 / 2)-\left(\mu / \sigma^{2}\right)\right)^{2}+2 r / \sigma^{2}} . \quad$ Analyzing this result yields the following propositions, of which the details of proof are attached in the Appendix.

Proposition 1. The abandonment boundary of the private sector $\left(X_{B}\right)$ is less than the operating cost $(f)$.

Proposition 1 implies that the private sector should not abandon the project immediately if the cash flow value is slightly below the operating $\operatorname{cost}\left(r-\mu / r \beta_{2} / \beta_{2}-1 f<X<f\right)$, but if the cash flow continues to deteriorate to some degree $\left(X<r-\mu / r \beta_{2} / \beta_{2}-1 f\right)$, the private sector should abandon the project. This result is very interesting. Why does the private sector not immediately abandon the project when the cash flow cannot cover the operating costs? The answer is uncertainty. Although the project's cash flow might not currently cover the operating costs, the situation could change and this could in turn yield future benefits. Abandoning the project would mean the private sector would lose this potential opportunity, so it will try to keep the project alive. However, the private sector will not keep the project going unconditionally. If the cash flow of the project becomes so dire that there is virtually no chance of improvement, the private sector will abandon the project.

Proposition 2. The abandonment boundary of the private sector increases with the operating cost $(f)$ and the risk-free rate $(r)$, but decreases with the expected rate of return $(\mu)$ and the volatility of the cash flow $(\sigma)$.

Proposition 2 implies that the abandonment boundary of the private sector is affected by the operating cost, the riskfree rate, the expected rate of return, and the volatility of the cash flow. Nevertheless, these factors have different 
TABLE 1: Explanations of key parameters.

\begin{tabular}{|c|c|}
\hline Notations & Explanations \\
\hline$I$ & The construction cost \\
\hline$\rho$ & The probability of completion risk \\
\hline$X \mathrm{~d} t$ & The accumulative cash flow in time interval $\mathrm{d} t$ \\
\hline$\mu$ & The risk-neutral expected rate of return \\
\hline$r$ & The risk-free rate \\
\hline$\sigma$ & The volatility rate of cash flow \\
\hline$f \mathrm{~d} t$ & The accumulative operation cost in time interval $\mathrm{d} t$ \\
\hline$\tau$ & The tax rate \\
\hline$\alpha$ & The default loss rate \\
\hline$X_{I}$ & The investment boundary when the private sector only uses equity capital \\
\hline $\bar{X}_{I}$ & The investment boundary when the private sector uses both equity and debt capital \\
\hline$X_{B}$ & The default boundary when the private sector only uses equity capital \\
\hline $\bar{X}_{B}$ & The default boundary when the private sector uses both equity and debt capital \\
\hline$V(X)$ & The option value of the project \\
\hline$E(X)$ & The option value of equity \\
\hline$D(X)$ & The option value of debt \\
\hline
\end{tabular}

influences on the abandonment boundary. A higher operating cost and risk-free rate will trigger the private sector to abandon the project earlier because both factors increase the costs of keeping the project alive. By contrast, a higher expected rate of return and volatile cash flow will make the private sector less likely to abandon the project since a higher expected rate of return means there is a bright future for the project, and greater volatility implies there is more opportunity for the project to turn around.

2.2.2. The Construction Period. During the construction period, the project faces the completion risk with the probability of $\rho \mathrm{d} t, 0<\rho<1$. Once the completion risk occurs, suppose the residual value of the project equals 0 . Since there is completion risk and uncertainty about the future cash flow, a rational private sector will not invest until the expected cash flow of the project becomes large enough. Suppose this investment boundary is $X_{I}$ and the expected value of the project is $V(X)$. There is no cash flow during the construction period, so the expected value of the project $V(X)$ satisfies the following Bellman equation:

$$
r V(X) \mathrm{d} t=E(\mathrm{~d} V(X)) .
$$

According to Ito's lemma, equation (7) can be translated into the following DE:

$$
r V(X)=\frac{1}{2} \sigma^{2} X^{2} \frac{\partial^{2} V}{\partial X^{2}}+\mu X \frac{\partial V}{\partial X}+\rho(0-V(X)) .
$$

Comparing equation (8) with (2), there is an extra item $\rho(0-V(X))$ in equation (8), which means a drop in the project's value once the completion risk occurs. By solving the DE, the expression of $V(X)$ can be deducted as follows:

$$
V(X)=B_{1} X^{\gamma_{1}}+B_{2} X^{\gamma_{2}}
$$

In the expression of $V(X), \gamma_{1}$ and $\gamma_{2}$ are the roots of the quadratic equation $\sigma^{2} / 2\left(x^{2}-x\right)+\mu x-r-\rho=0$ and they satisfy $\gamma_{1}>0$ and $\gamma_{2}<0 . B_{1}$ and $B_{2}$ are constants to be solved. Because when the cash flow of the project equals $0(X=0)$, the value of the project will also be equal to 0 , namely $V(X)=0$, it must satisfy that $B_{2}=0$. Besides, just like in the above analyses, $V(X)$ also has to meet the conditions of value matching in equation (10) and smooth passing in equation (11).

$$
\begin{gathered}
V\left(X_{I}\right)=(1-\rho) V_{O}\left(X_{I}\right)-I \\
\left.\frac{\partial V(X)}{\partial X}\right|_{X=X_{I}}=\left.(1-\rho) \frac{\partial V_{O}(X)}{\partial X}\right|_{X=X_{I}}
\end{gathered}
$$

Combining equations (9)-(11), we can determine the expression of $V(X)$ as follows:

$$
V(X)=\left[\left(\frac{1-\tau}{r-\mu} X_{I}-\frac{1-\tau}{r} f-\left(\frac{1-\tau}{r-\mu} X_{B}-\frac{1-\tau}{r} f\right)\left(\frac{X_{I}}{X_{B}}\right)^{\beta_{2}}\right)(1-\rho)-I\right]\left(\frac{X}{X_{I}}\right)^{\gamma_{1}}
$$

Also, the expression of $X_{I}$ is determined by the following equation:

$$
\left(1-\frac{\beta_{2}}{\gamma_{1}}\right) \frac{1-\tau}{r} \frac{1}{\beta_{2}-1} f\left(\frac{X_{I}}{X_{B}}\right)^{\beta_{2}}-\left(1-\frac{1}{\gamma_{1}}\right) \frac{1-\tau}{r-\mu} X_{I}+\frac{1-\tau}{r} f+\frac{I}{1-\rho}=0
$$


Lemma 1. The investment boundary $X_{I}$ satisfies that $X_{I}>\left(\gamma_{1} / \gamma_{1}-\beta_{2}\right)^{1 / \beta_{2}} X_{B}$.

Although a closed-form solution of the investment boundary cannot be derived, Lemma 1 sets out its value's reasonable range. This range relates to the abandonment boundary: the larger the abandonment boundary, the greater the need for the cash flow value to attract private sector investment in the project. A similar result can be found in Sundaresan et al.'s work [33]. They studied how corporations should dynamically adjust their capital structure and found that there exists a linear relationship between the default boundary and the investment boundary [33]. By analyzing equation (13), a proposition is promoted.

Proposition 3. The relation between the investment boundary $\left(X_{I}\right)$ and the completion risk probability $(\rho)$ depends on the relative value of the construction cost (I). If $I>I^{\prime}$ $\left(I^{\prime}=\left(1-\tau / r-\mu X_{I}-\beta_{2} / \beta_{2}-11-\tau / r f\left(X_{I} / X_{B}\right) \quad \beta_{2}\right) / 2 \sigma^{2}\right.$ $\left(\left(\left(1 / 2-\mu / \sigma^{2}\right)^{2}+r / \sigma^{2}\right) \sqrt{\left(1 / 2-\mu / \sigma^{2}\right)^{2}+2 r /} \quad \sigma^{2}+(1 / 2-\right.$ $\left.\left.\left.\mu / \sigma^{2}\right)\left(\left(1 / 2-\mu / \sigma^{2}\right)^{2}+2 r / \sigma^{2}\right)\right)\right)$, the investment boundary increases with the completion risk probability; if $I \leq I^{\prime}$, there exists a completion risk probability $\rho_{1}$, and when $\rho<\rho_{1}$, the investment boundary $X_{I}$ decreases with the completion risk probability. However, when $\rho \geq \rho_{1}$, the investment boundary increases with the completion risk probability. Moreover, the investment boundary of the project $\left(X_{I}\right)$ increases with the operating cost $(f)$.

Proposition 3 demonstrates how the investment boundary changes with the completion risk probability and operating cost. The investment boundary reflects the condition when the private sector should invest in the project: if this boundary value is lower, the private investor should make an earlier investment decision. The results show that if the construction cost is high, the investment boundary will increase with the completion risk. That is to say that a higher completion risk will make the private sector hesitant to invest in the project. This result is consistent with our intuition: since the completion risk will make the private sector lose their construction investment, a high construction cost will make the private sector more cautious about the completion risk (Chan et al. 2014); [16]. However, if the construction cost is low, there exists a small interval during which time the private sector will tolerate the completion risk, namely, it will invest earlier when perceiving the probability of a completion risk increases in the future. The underlying reasoning is that if the completion risk probability is low at the moment, then the private sector will invest earlier fearing that it will become high. Outside of this interval, the private sector will return to being cautious about the completion risk. That is, it will delay its investment when it feels the completion risk probability will increase in the future. A numerical analysis will be conducted later to analyze the relation between $X_{I}$ and other parameters.

2.3. Financing by Debt and Equity Capital Simultaneously. This section will discuss the scenario that the private sector uses both equity and debt capital to provide financing for the construction cost. Suppose the debt is a perpetual zero coupon bond with coupon $C$. The benefit of using debt is that it is tax deductible, but debt may also increase the likelihood of the project defaulting if the private sector cannot make the coupon payment. Suppose the default boundary that keeps the private sector operating the project is $\bar{X}_{D}$; when the cash flow of the project reaches this boundary condition, the private sector will default, and the project will be turned over to the debt holder. However, since there are frictions during the transfer process, a fraction of the cash flow value will be lost: suppose this loss is equal to $\alpha \bar{X}_{D}, 0<\alpha<1$. After the private sector defaults, the residual value of the project is equal to $E\left[\left((1-\alpha) \bar{X}_{D}-f\right)\right]=1-\alpha / r \bar{X}_{D}-f / r$.

2.3.1. The Operation Period. During the operation period, the project value is denoted as $\bar{V}_{O}(X)$, the debt value is $\bar{D}_{O}(X)$, and the equity value is $\bar{E}_{O}(X)$. The equity value $\bar{E}_{O}(X)$ satisfies the following Bellman equation:

$$
r \bar{E}_{O}(X) \mathrm{d} t=(1-\tau)(X-C-f) \mathrm{d} t+E\left(d \bar{E}_{O}(X)\right) .
$$

According to Ito's lemma, equation (14) can be translated into the following $\mathrm{DE}$ :

$$
\begin{gathered}
\frac{1}{2} \sigma^{2} X^{2} \frac{\partial^{2} \bar{E}_{O}(X)}{\partial X^{2}}+\mu X \frac{\partial \bar{E}_{O}(X)}{\partial X}-r \bar{E}_{O}(X) \\
+(1-\tau)(X-f-C)=0 .
\end{gathered}
$$

The expression of the equity value can be derived by solving the DE, as follows:

$$
\bar{E}_{O}(X)=\frac{1-\tau}{r-\mu} X-\frac{1-\tau}{r}(f+C)+C_{1} X^{\beta_{1}}+C_{2} X^{\beta_{2}} .
$$

In this equation, $C_{1}$ and $C_{2}$ are the constants to be solved. Since the private sector's probability of default is 0 when the value of the cash flow is high enough, $C_{1}$ must be equal to 0 . Similarly, $\bar{E}_{O}(X)$ should satisfy the value matching condition (17) and smooth passing condition (18).

$$
\begin{array}{r}
\bar{E}_{O}\left(\bar{X}_{D}\right)=0, \\
\left.\frac{\partial \bar{E}_{O}(X)}{\partial X}\right|_{X=\bar{X}_{D}}=0 .
\end{array}
$$

Combining equations (16)-(18), the analytic solution of $\bar{E}_{O}(X)$ and $\bar{X}_{D}$ can be derived. 


$$
\begin{aligned}
\bar{E}_{O}(X)= & \frac{1-\tau}{r-\mu} X-\frac{1-\tau}{r}(C+f) \\
& -\left(\frac{1-\tau}{r-\mu} \bar{X}_{D}-\frac{1-\tau}{r}(C+f)\right)\left(\frac{X}{\bar{X}_{D}}\right)^{\beta_{2}}, \\
\bar{X}_{D}= & \frac{r-\mu}{r} \frac{\beta_{2}}{\beta_{2}-1}(f+C) .
\end{aligned}
$$

By analyzing the above results, the following proposition is made.

Proposition 4. Compared with the all equity capital scenario, the private sector will abandon the project earlier if they use debt capital.

This proposition can be easily proven, but its underlying meaning is significant. On the one hand, using debt capital can bring tax shield benefits to the private sector, but on the other hand, using debt capital increases the likelihood of private sector default. When the private sector decides to use debt capital, it should consider these two possible outcomes. This proposition also suggests that there is an agency problem between the equity holder (the private sector) and the debt holder. When the cash flow of the project deteriorates, the private sector will not keep the project going longer when using debt capital than it would if it were using all equity capital because keeping the project going longer will benefit the debt holder to the detriment of the equity holder (the private sector). This agency problem between equity holders and debt holders has been widely studied in corporate finance literature [33-36]).

The value of the project $\bar{V}_{O}(X)$ satisfies the following Bellman equation:

$$
r \bar{V}_{O}(X) \mathrm{d} t=[(1-\tau)(X-f)+\tau C] \mathrm{d} t+E\left(d \bar{V}_{O}(X)\right) .
$$

In a similar way, this equation can be translated into the following DE:

$$
\begin{gathered}
\frac{1}{2} \sigma^{2} X^{2} \frac{\partial^{2} \bar{V}_{O}(X)}{\partial X^{2}}+\mu X \frac{\partial \bar{V}_{O}(X)}{\partial X}-r \bar{V}_{O}(X) \\
+(1-\tau)(X-f)+\tau C=0
\end{gathered}
$$

by solving this $\mathrm{DE}$

$$
\bar{V}_{O}(X)=\frac{1-\tau}{r-\mu} X+\frac{\tau C}{r}-\frac{1-\tau}{r} f+D_{1} X^{\beta_{1}}+D_{2} X^{\beta_{2}},
$$

where $D_{1}$ and $D_{2}$ are the constants to be solved. When the cash flow of the project is very large, it is rare for the private sector to default, so $D_{1}=0$. However, once the private sector defaults, the value of the project satisfies that

$$
\bar{V}_{O}\left(\bar{X}_{D}\right)=\frac{1-\alpha}{r} \bar{X}_{D}-\frac{f}{r} .
$$

Combining equations (22) and (23), the expression of $\bar{V}_{O}(X)$ can be derived.

$$
\begin{aligned}
\bar{V}_{O}(X)= & \frac{1-\tau}{r-\mu} X+\frac{\tau C}{r}-\frac{1-\tau}{r} f \\
& +\left[\left(\frac{1-\alpha}{r}-\frac{1-\tau}{r-\mu}\right) \bar{X}_{D}-\frac{\tau}{r}(C+f)\right]\left(\frac{X}{\bar{X}_{D}}\right)^{\beta_{2}} .
\end{aligned}
$$

Therefore, the expression of $\bar{D}_{O}(X)$ is

$$
\begin{aligned}
\bar{D}_{O}(X) & =\bar{V}_{O}(X)-\bar{E}_{O}(X) \\
& =\frac{C}{r}+\left(\frac{1-\alpha}{r} \bar{X}_{D}-\frac{C+f}{r}\right)\left(\frac{X}{\bar{X}_{D}}\right)^{\beta_{2}} .
\end{aligned}
$$

2.3.2. The Construction Period. During the construction period, just like in the analysis of all equity capital scenario, there is an investment boundary, $\bar{X}_{I}$. Only when the cash flow of the project is higher than this boundary will the private sector invest in the project. Suppose the value of the project is $\bar{V}(X)$ and the debt value is $\bar{D}(X) . \bar{V}(X)$ satisfies the following Bellman equation:

$$
r \bar{V}(X) \mathrm{d} t=E(\mathrm{~d} \bar{V}(X)) .
$$

According to Ito's lemma, this equation can be translated into the following equation:

$$
r \bar{V}(X)=\frac{1}{2} \sigma^{2} X^{2} \frac{\partial^{2} \bar{V}(X)}{\partial X^{2}}+\mu X \frac{\partial \bar{V}(X)}{\partial X}+\rho(0-\bar{V}(X))
$$

Solving this equation, we can get

$$
\bar{V}(X)=F_{1} X^{\gamma_{1}}+F_{2} X^{\gamma_{2}},
$$

Where $F_{1}$ and $F_{2}$ are the constants to be solved. Since when $X$ equals $0, \bar{V}(X)$ also equals 0 , this implies that $F_{2}=0$. Moreover, $\bar{V}(X)$ has to satisfy the value matching condition (29) and the smooth passing condition (30) at the default boundary. That is,

$$
\begin{gathered}
\bar{V}\left(\bar{X}_{I}\right)=(1-\rho) \bar{V}_{O}\left(\bar{X}_{I}\right)-I \\
\left.\frac{\partial \bar{V}(X)}{\partial X}\right|_{X=\bar{X}_{I}}=\left.(1-\rho) \frac{\partial \bar{V}_{O}(X)}{\partial X}\right|_{X=\bar{X}_{I}}
\end{gathered}
$$

Combining equations (28)-(30), we get

$$
\bar{V}(X)=\left\{(1-\rho)\left[\frac{1-\tau}{r-\mu} \bar{X}_{I}+\frac{\tau C}{r}-\frac{1-\tau}{r} f+A_{1} \bar{X}_{D}\left(\frac{\bar{X}_{I}}{\bar{X}_{D}}\right)^{\beta_{2}}\right]-I\right\}\left(\frac{X}{\bar{X}_{I}}\right)^{\gamma_{1}}
$$


where $A_{1}=\left(1-\alpha / r+1 / r-\mu\left(\tau / \beta_{2}-1\right)\right)$, and it is obvious that $A_{1}<0$.

The investment boundary $\bar{X}_{I}$ satisfies the following equation:

$$
\begin{gathered}
\left(1-\frac{\beta_{2}}{\gamma_{1}}\right) A_{1} \bar{X}_{D}^{1-\beta_{2}} \bar{X}_{I}^{\beta_{2}}+\left(1-\frac{1}{\gamma_{1}}\right) \frac{1-\tau}{r-\mu} \bar{X}_{I} \\
+\frac{\tau C}{r}-\frac{(1-\tau)}{r} f-\frac{I}{1-\rho}=0 .
\end{gathered}
$$

By analyzing equation (32), a proposition can be made.

Proposition 5. When using both debt and equity capital, the relation between the investment boundary $\left(\bar{X}_{I}\right)$ and the completion risk probability $(\rho)$ depends on the relative value of the construction cost (I). If $I>I^{\prime \prime}$ $\left(I^{\prime \prime}=\beta_{2} A_{1} \bar{X}_{D}^{1-\beta_{2}} \bar{X}_{I}^{\beta_{2}}+1-\tau / r-\mu \bar{X}_{I} / 2 \sigma^{2} \quad\left(\left(\left(1 / 2-\mu / \sigma^{2}\right)^{2}+\right.\right.\right.$ $\left.r / \sigma^{2}\right) \sqrt{\left(1 / 2-\mu / \sigma^{2}\right)^{2}+2 r / \sigma^{2}}+\left(1 / 2-\mu / \sigma^{2}\right)\left(\left(1 / 2-\mu / \sigma^{2}\right)^{2}\right.$ $\left.+2 r\left(\sigma^{2}\right)\right)$ ), the investment boundary increases with the completion risk probability; if $I \leq I^{\prime \prime}$, there exists a completion risk probability $\rho_{2}$. When $\rho<\rho_{2}$, the investment boundary decreases with the completion risk probability; however, when $\rho \geq \rho_{2}$, the investment boundary increases with the completion risk probability. Moreover, the investment boundary also increases with the operating cost $(f)$ and default cost $(\alpha)$.

Just like the argument in Proposition 3, Proposition 5 also shows that there exists an interval during which time the private sector will tolerate the completion risk. Besides, Proposition 5 implies that high operating and default costs will deter the private sector from investing in the project, which aligns with our theory that high operating and default costs mean the project's future outlook is relatively poor.

Proposition 6. When $X_{I}-\bar{X}_{I}<k C\left(k=\tau / 1-\tau r-\mu / r \beta_{2}\right.$ ) $\left.\beta_{2}-1\right)$, it is satisfied that $I^{\prime}<I^{\prime \prime}$ and $\rho_{1}<\rho_{2}$; otherwise, it is satisfied that $I^{\prime} \geq I^{\prime \prime}$ and $\rho_{1} \geq \rho_{2}$.

The value of $\left(I^{\prime}, \rho_{1}\right)$ and $\left(I^{\prime \prime}, \rho_{2}\right)$ represents the level of tolerance of the private sector for the completion risk. In Proposition 6, $k C$ stands for the added default boundary due to using debt capital when we compare $\bar{X}_{D}$ and $X_{B}$. So, Proposition 6 can be explained as follows: if the reduced investment boundary is less than the added default boundary, using debt capital will make the private sector more tolerant of the completion risk; otherwise, using debt capital will make the private sector less tolerant of the completion risk.

Since the analytic expression of $\bar{X}_{I}$ cannot be derived, a numerical analysis will be conducted to investigate its relation to other parameters.

2.4. The Optimal Capital Structure of the Project. As in the above analyses, when using debt capital, the private sector should balance the benefits and costs that are brought about by the debt. There exists an optimal debt level that will maximize the project's value. Suppose the optimal debt level is $C^{*}$, which can be derived by solving the following maximum problem:

$$
\underset{C}{\operatorname{Max}}\left(\bar{V}_{O}(X)\right)
$$

By solving this maximum problem, the following proposition can be presented.

Proposition 7. The optimal debt level of the project can be expressed as

$$
C^{*}=\frac{r}{r-\mu} \frac{\beta_{2}-1}{\beta_{2}}\left(\frac{A_{2}}{\tau}\right)^{1 / \beta_{2}} X-f,
$$

where $A_{2}=r\left(\beta_{2}-1\right) / \tau A_{1}$. The optimal value of the project in the operation period is

$$
\bar{V}_{O}(X)=B X-\frac{f}{r},
$$

where $B=1 / r-\mu\left[1-\tau+\tau\left(A_{2} / \tau\right)^{1 / \beta_{2}}\right]$.

From the expression of the optimal debt level $\left(C^{*}\right)$, it can be found that the optimal debt level increases with the value of the cash flow. That is to say, the higher the project's cash flow is, the more debt capital the private sector should use. The underlying reasoning is that using more debt can bring more tax shield benefits to the private sector. However, the optimal debt level decreases with the operating cost, which implies that if the operating cost of the project is high, the private sector should use less debt capital. Because the probability of the private sector defaulting is already high under high operating costs, using debt capital will cause the situation to further deteriorate.

This proposition shows that the optimal value of the project is equal to the present value of the cash flow deducted from the present value of the operating cost. However, there are different discount factors between the cash flow and operating cost. While the discount factor of the operating cost only contains the risk-free rate, the discount factor of the cash flow $(B)$ contains the expected rate of return, volatility, and tax rate except for the risk-free rate. This result implies that it may be improper for the traditional NPV method to set the same discount for the cash flow and operating cost. Besides, the traditional NPV calculation method has long been criticized by scholars because it excludes the flexibilities that are contained in the project $[20,21]$.

Corollary 1. The optimal debt level $C^{*}$ increases with the tax rate $\tau$ and decreases with the default loss rate $\alpha$.

This corollary implies that the private sector should use more debt capital in those countries with higher tax rates so that it can offset some of the tax costs through the debt's tax shield. However, if there is a larger default cost for the project, then the private sector should use less debt capital to avoid a potentially great loss.

Corollary 2. Under the optimal debt level $C^{*}$, the value of the investment boundary, debt, and project is, respectively, 


$$
\begin{aligned}
\bar{X}_{I} & =\frac{\gamma_{1}}{B(1-\rho)\left(\gamma_{1}-1\right)}\left[(1-\rho) \frac{f}{r}+I\right], \\
\bar{D}(X) & =(1-\rho)\left[\frac{C^{*}}{r}+\left(\frac{1-\alpha}{r} \bar{X}_{D}-\frac{C^{*}+f}{r}\right)\left(\frac{\bar{X}_{I}}{\bar{X}_{D}}\right)^{\beta_{2}}\right]\left(\frac{X}{\bar{X}_{I}}\right)^{\gamma_{1}}, \\
\bar{V}(X) & =\left[(1-\rho) B \bar{X}_{I}-\frac{1-\rho}{r} f-I\right]\left(\frac{X}{\bar{X}_{I}}\right)^{\gamma_{1}} .
\end{aligned}
$$

In this corollary, $\left(X / \bar{X}_{I}\right)^{\gamma_{1}}$ can be seen as the present value of a claim paying $1 \$$ contingent on the firm value reaching the investment boundary $\bar{X}_{I}$ [37]. According to this corollary, the investment boundary relates to the construction and operating costs: the higher the cost, the higher the investment boundary.

2.5. Numerical Analyses. In this section, how different parameters, including the probability of the completion risk, the volatility, the risk-free interest rate, the expected rate of return, and the tax rate, affect the investment boundary of the private sector is explored.

First, the relation between the probability of the completion risk and the investment boundary is investigated (see Figure 1). The value of the volatility is set at $0.5(\sigma=0.5)$, which is reasonable because it is difficult to predict the cash flow of PPP projects precisely $[5,38]$. The value of the expected rate of return of the project is set at $0.08(\mu=0.08)$, the value of the tax rate is set at $0.3(\tau=0.3)$, and the value of the default cost rate is set at $0.6(\alpha=0.6)$. This last value is relatively high because there exists asset specificity in PPP projects-once the original investors abandon the project, the project will be largely devalued. The value of the risk-free interest rate is set at 0.1 $(r=0.1)$, and the values of the construction cost and the operating cost are set at 2 and 1 million dollars, respectively $(I=2$ and $f=1)$. From Figure 1 , it can be seen that the investment boundary decreases slightly at first and then increases with the probability of the completion risk. Therefore, Propositions 3 and 5 are verified. These findings can deal with the divergence existing in previous studies that investigated the completion risk allocation between the government and the private investor $[16,18,19]$. That is, when the probability of the completion risk is low, it is advisable to allocate the completion risk to the private investor, which aligns with the findings of Chan et al. [19] and Mouraviev and Kakabadse [16]; when the probability of the completion risk is high, it will be better to share the completion risk between the private investor and the government, which is the conclusion of Park and Chang [18]. Moreover, it can also be seen that using debt capital can motivate the private sector to invest sooner, but this effect is reduced when the probability of the completion risk increases.

Second, allow the other parameters' values to remain unchanged and set the value of the probability of the completion risk at $0.5(\rho=0.5)$, which is reasonable since many PPP projects have displayed various problems during the construction period, such as delays and

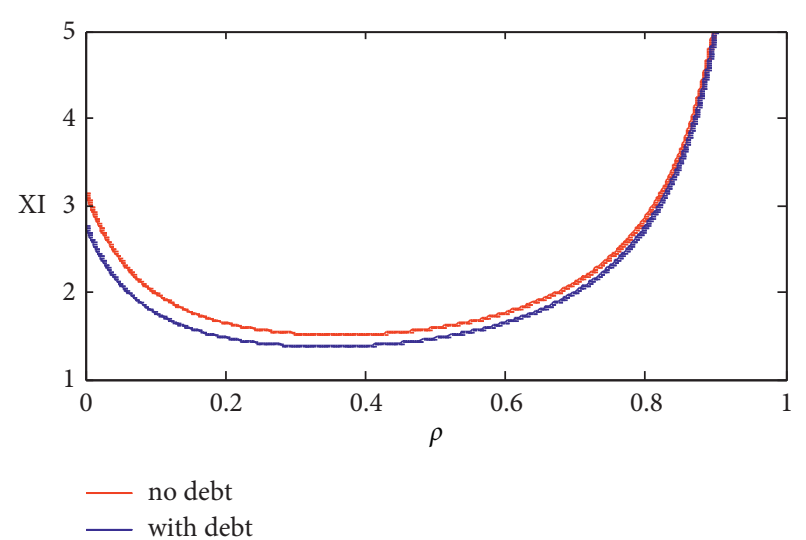

Figure 1: The probability of the completion risk $(\rho)$.

overrunning costs. The relation between the volatility and investment boundary is displayed in Figure 2. Using Figure 2, it can be shown that whether the private sector uses debt capital (the blue line) or not (the red line), the investment boundary value of the private sector increases with the volatility. Moreover, the investment boundary value increases more quickly when using debt capital than when only using equity capital. Furthermore, under the same cash flow volatility, the private sector tends to invest sooner when using debt capital than it does when using equity capital alone. These results imply that the more the cash flow fluctuates, the better it is for the private sector to postpone its investment. The reasoning is that waiting can allow the private sector to select a better investment opportunity and the volatility can increase this waiting option's value. Besides, because the private sector has limited liability if the project deteriorates and has a right to the windfall revenue, using debt capital can motivate the private sector to invest sooner. However, using debt capital will also increase the likelihood of private sector default, which causes the private sector to lose the opportunity to potentially raise windfall revenue, so the incentive effect of using debt capital will be offset with the increase of the volatility.

Third, set the value of the volatility to $0.5(\sigma=0.5)$ and keep the other parameters' values unchanged; the relation between the risk-free interest rate and the investment boundary is displayed in Figure 3. From this figure, it is apparent that reducing the risk-free interest rate, such as the bank deposit rate and the treasury bond rate, can motivate the private sector to invest in a PPP project. This result is consistent with the findings of Owusu-Manu et al. [38] who studied how sociopolitical and economic factors affect private sector participation in PPP projects. In their study, they argued that reducing the risk-free interest rate can lower the opportunity cost of the private sector [38]. Moreover, it can also be seen that the wedge between the two investment boundaries grows with the risk-free interest rate. Although a higher risk-free interest rate will increase the opportunity cost of both debt and equity capital, the "limited liability" makes the private sector care less about the debt capital, which causes the wedge between the two investment boundaries to grow. 


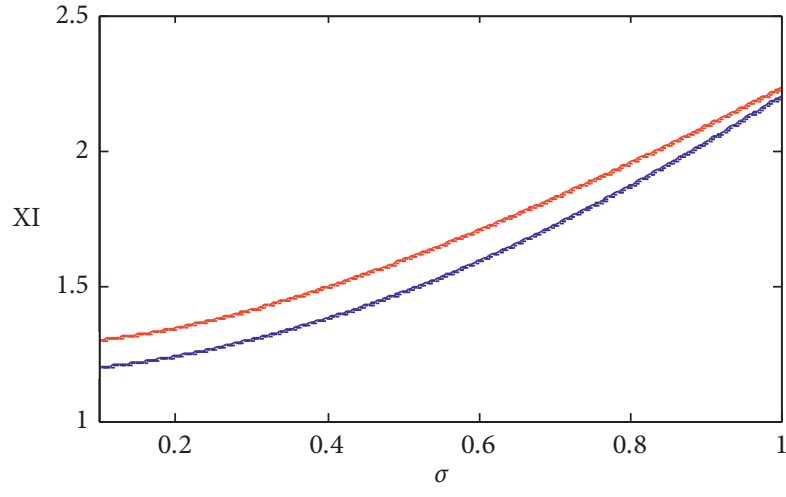

Figure 2: Volatility $(\sigma)$.

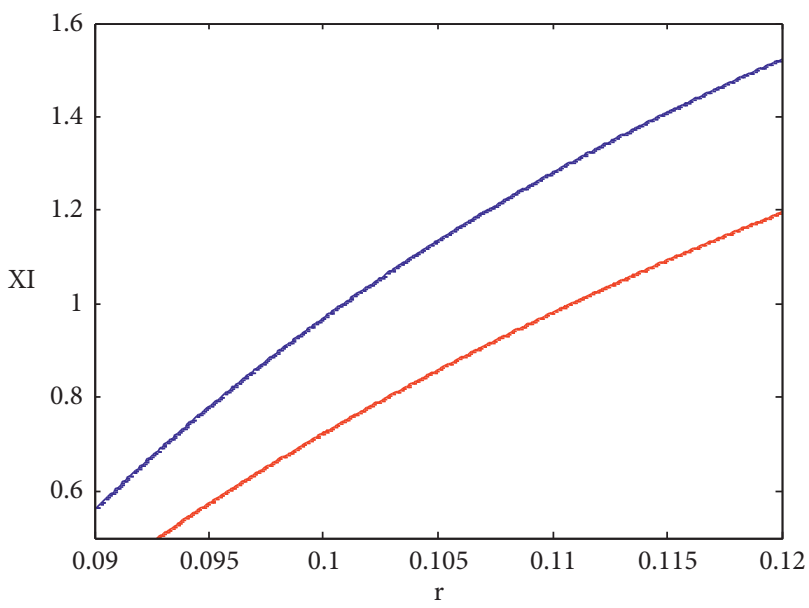

FIGURE 3: Risk-free interest rate $(r)$.

Fourth, keeping the other parameters' values as they are, the relation between the expected rate of return and the investment boundary is presented in Figure 4. It demonstrates that the investment boundary decreases with the expected rate of return no matter whether debt is used or not. This result supports both intuition and practice since a high expected rate of return means that the project can yield plenty of benefits in the future, which in turn incentivizes the private sector to invest in the project. Besides, it can be also found that the incentive effect of using debt capital is reduced as the expected rate of return increases. The underlying reason is that a highly profitable project will attract the private sector's investment regardless of whether it uses debt capital.

Fifth, keeping the other parameters' values unchanged, the relation between the tax rate and the investment boundary is displayed in Figure 5. It can be seen that the investment boundary increases quickly with the tax rate. However, due to the tax shield effect of the debt capital, the investment boundary's increase is relatively slow when using debt capital.

2.6. Managerial Implications. Due to the highly uncertain cash flow of PPP projects, it is hard for the private sector to

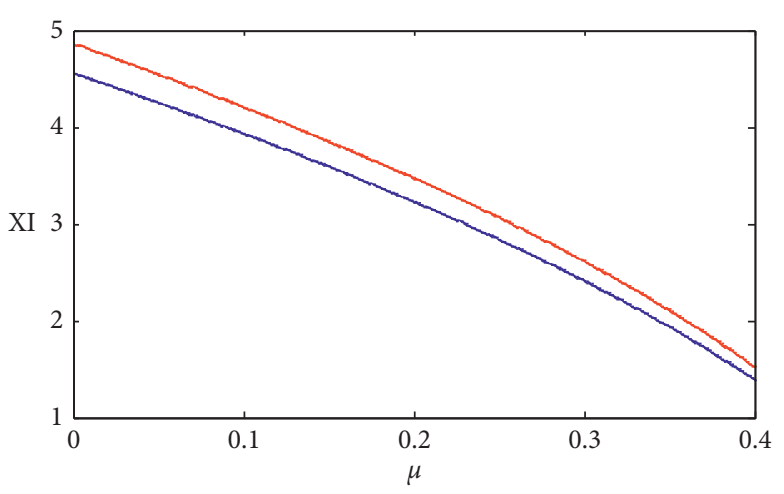

FIgURE 4: Expected rate of return $(\mu)$.

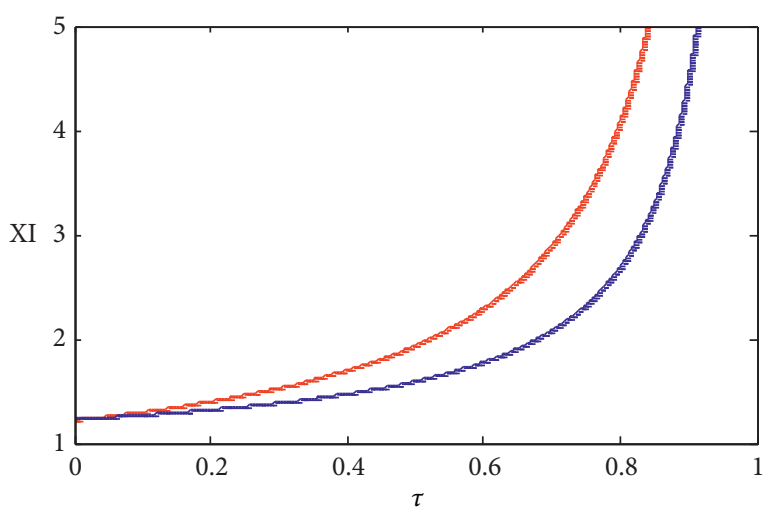

Figure 5: Tax rate $(\tau)$.

make an investment decision and design an adequate capital structure, especially when it must face the completion risk. This study can provide some useful management insights into the investment decision for the private sector. First, the private sector should comprehensively evaluate its risk tolerance from two aspects: the construction cost and the probability of the completion risk. If both aspects are acceptable to the private sector, it should invest in the project as soon as possible; however, if one of them is unacceptable, the private sector should delay their investment, except if the potential benefits of the project are significantly great. Second, the private sector should use more debt capital in those countries with a high tax rate to make full use of the tax shield benefits.

This study can also provide some useful suggestions for governments to induce the private sector to invest in PPP projects. First, the government should take some measures to lower the risk-free interest rate, which can reduce both the investment and the default boundaries of the private sector. Empirically, Owusu-Manu et al. [39] found that cutting interest rates attracts more private investors. Second, the government should lower its tax rate for PPP projects, which can effectively induce the private sector to invest in them. This measure can also undermine the private sector's motivation to use more debt capital to reap the tax shield benefits, which can reduce the private sector's likelihood of default. Third, the government should take steps to improve 
and expand the debt capital market so that the private sector can raise enough debt capital when it invests in PPP projects. Although a more robust debt capital market can induce the private sector to invest in PPP projects, using debt capital may increase the private sector's likelihood of default. Therefore, the government should implement some monitoring measures at the same time. Finally, a proper completion risk allocation plan between the government and the private investor should be arranged based on the evaluation of the probability of the completion risk. When the probability of the completion risk is low, it is advisable to allocate the completion risk to the private investor; when the probability of the completion risk is high, it will be better to share the completion risk between the private investor and the government.

\section{Conclusions}

This study investigated how completion risk and project profitability affect the investment decision of the private sector in PPP projects. The results show that there exists a non-monotonic relationship between the probability of completion risk and the investment boundary of the private sector. This finding demonstrates the importance of a proper risk allocation between the government and the private investor. Specifically, when the probability of the completion risk is low, it is advisable to allocate the completion risk to the private investor; when the probability of the completion risk is high, it will be better to share the completion risk between the private investor and the government. Besides, the results indicate that a lower expected rate of return and a higher volatility of cash flow will deter the private sector from investing in PPP projects. Therefore, lowering the riskfree interest and tax rates can encourage the private sector to invest in PPP projects. These results can offer some useful suggestions for the government to take effective measures to attract the private sector's participation in PPP projects.

However, several of this study's limitations need to be nominated for further extension. First, only the completion risk and project profitability-related factors are considered in this study; how other critical factors, like government commitment $[7,8]$ and organization strategies [6], affect the investment decision of the private sector needs to be studied further. Second, because of the lack of available data for similar projects to properly estimate the cash flow volatility parameter, the application of the real option method used in this study for practice is still on the way, and future research can explore methods to estimate the cash flow volatility parameter. Finally, as Bitsch et al. [40] and Park and Chang [18] have argued, since the main obstacle to studying the private sector's participation in PPP projects is the lack of available data, the empirical verification of the propositions proposed in this study will be conducted when the related data become available in the future.

\section{Appendix}

Proof of Proposition 1
$X_{B}-f=\left(r-\mu / r \beta_{2} / \beta_{2}-1-1\right) f<\left(\beta_{2} / \beta_{2} \quad-1-1\right) f=$ $1 / \beta_{2}-1 f<0$ (QED).

Proof of Proposition 2

Since $\partial X_{B} / \partial f=r-\mu / r \beta_{2} / \beta_{2}-1>0$, the relation between the private sector's abandonment boundary and the operating cost is proven. Similarly, we can derive $\partial X_{B} / \partial r$, $\partial X_{B} / \partial \sigma$ and $\partial X_{B} / \partial \mu$, respectively, and analyze whether they are positive or negative, as follows.

$$
\partial X_{B} / \partial r=\mu / r^{2}\left(\beta_{2} / \beta_{2}-1\right) f+(r-\mu / r) 1 /\left(\beta_{2}-1\right)^{2}
$$

$1 / \sigma^{2}\left((1 / 2)-\left(\mu / \sigma^{2}\right)^{2}+2 r / \sigma^{2}\right)>0$, so the relation between the private sector's abandonment boundary and the risk-free interest rate is proven. Since $\partial X_{B} / \partial \sigma=r-\mu / r(-1 /$ $\left.\left(\beta_{2}-1\right)^{2}\right) \partial \beta_{2} / \partial \sigma f, \quad \partial \beta_{2} / \partial \sigma=2 / \sqrt{\left(1 / 2-\mu / \sigma^{2}\right)^{2}+2 r / \sigma^{2}}$ $\left.\left(\mu / \sigma^{3} \sqrt{(1 / 2-} \mu / \sigma^{2}\right)^{2}+2 r / \sigma^{2}-\mu / \sigma^{3}\left(1 / 2-\mu / \sigma^{2}\right)+r / \sigma^{3}\right)>0$, $\partial X_{B} / \partial \sigma<0$. The relation between the abandonment boundary of the private sector and the volatility of the cash flow is proven. $\partial X_{B} / \partial \mu=-1 / r \beta_{2} / \beta_{2}-1 f+r-\mu / r\left(-1 /\left(\beta_{2}\right.\right.$ $\left.-1)^{2}\right) \partial \beta_{2} / \partial \mu f$. Plugging the equation $\partial \beta_{2} / \partial \mu=\beta_{2} / \sigma^{2}$ $\sqrt{\left(1 / 2-\mu / \sigma^{2}\right)^{2}+2 r / \sigma^{2}}$ into the above equation, we get $\partial X_{B} / \partial \mu=-1 / r \beta_{2} / \beta_{2}-1 f\left(1+(r-\mu) 1 / \sigma^{2} \quad\left(\beta_{2}-1\right)\right.$ $\left.\sqrt{\left(1 / 2-\mu / \sigma^{2}\right)^{2}+2 r / \sigma^{2}}\right)>0$, which implies that the abandonment boundary of the private sector decreases with the expected rate of return of the project.

Proof of Lemma 1

Denote the function $F(x)$ as $F(x)=\left(1-\beta_{2} / \gamma_{1}\right) 1-\tau / r 1 /$ $\beta_{2}-1 f\left(x / X_{B}\right)^{\beta_{2}}-\left(1-1 / \gamma_{1}\right) 1-\tau / r-\mu x+1-\tau / r f, x>X_{B}$. It can be derived that $\partial F / \partial x=\left(1-\beta_{2} / \gamma_{1}\right) 1-\tau / r-\mu$ $\left(x / X_{B}\right)^{\beta_{2}-1}-\left(1-1 / \gamma_{1}\right) 1-\tau / r-\mu$. When $X_{B}<x<(1-$ $\left.1 / \gamma_{1} / 1-\beta_{2} / \gamma_{1}\right)^{1 / \beta_{2}-1} X_{B}, \partial F / \partial x>0$, the function $F(x)$ increases with $x$, so $F(x)>F\left(X_{B}\right)=I / 1-\rho>0$ in this interval. When $\quad x \geq\left(1-1 / \gamma_{1} / 1-\beta_{2} / \gamma_{1}\right)^{1 / \beta_{2}-1} X_{B}, \quad \partial F / \partial x \leq 0$, the function $F(x)$ decreases with $x$. Since the value of $F(x)$ is bigger than 0 , when $X_{B}<x<\left(1-1 / \gamma_{1} / 1-\beta_{2} / \gamma_{1}\right)^{1 / \beta_{2}-1} X_{B}$ (due to $F(x)>F\left(X_{B}\right)=I / 1-\rho$ ), the condition $X_{I}$ needs to satisfy that $X_{I} \geq\left(1-1 / \gamma_{1} / 1-\beta_{2} / \gamma_{1}\right)^{1 / \beta_{2}-1} X_{B}$ for the $F\left(X_{I}\right)$ to be equal to 0 . Moreover, because $\left(\gamma_{1} / \gamma_{1}-\beta_{2}\right)^{1 / \beta_{2}}>\left(\gamma_{1} /\right.$ $\left.\gamma_{1}-\beta_{2}\right)^{1 / \beta_{2}-1}>\left(\gamma_{1}-1 / \gamma_{1}-\beta_{2}\right)^{1 / \beta_{2}-1}, \quad\left(\gamma_{1} / \gamma_{1}-\beta_{2}\right)^{1 / \beta_{2}} X_{B}$ $>\left(\gamma_{1}-1 / \gamma_{1}-\beta_{2}\right)^{1 / \beta_{2}-1} X_{B} . F\left(\left(\gamma_{1} / \gamma_{1}-\beta_{2}\right)^{1 / \beta_{2}} X_{B}\right)=1-\tau / r$ $-\mu X_{B}\left(1-\left(1-1 / \gamma_{1}\right)\left(\gamma_{1} / \gamma_{1}-\beta_{2}\right)^{1 / \beta_{2}}\right)+I / 1-\rho$; since $\left(1-1 / \gamma_{1}\right) \quad \beta_{2}=1-\beta_{2} / \gamma_{1}+C_{\beta_{2}}^{2} 1 / \gamma_{1}^{2}-C_{\beta_{2}}^{3} 1 / \gamma_{1}^{3}+\ldots>1-\beta_{2} /$ $\gamma_{1}$, it can be derived that $1 /\left(1-1 / \gamma_{1}\right)>\left(\gamma_{1} / \gamma_{1}-\beta_{2}\right)^{1 / \beta_{2}}$, so $1 /\left(1-1 / \gamma_{1}\right)>\left(\gamma_{1} / \gamma_{1}-\beta_{2}\right)^{1 / \beta_{2}}>0$, so $F\left(\left(\gamma_{1} / \gamma_{1}-\beta_{2}\right)^{1 / \beta_{2}}\right.$ $\left.X_{B}\right)>0$, so $X_{I}$ needs to satisfy that $X_{I}>\left(\gamma_{1} / \gamma_{1}-\beta_{2}\right)^{1 / \beta_{2}} X_{B}$. Proof of Proposition 3

From the derivation of Lemma 1, we know that $\partial F / \partial X_{I}<0$. Besides, $\partial F / \partial \rho=-1-\tau / r-\mu X_{I}-\beta_{2} / \beta_{2}-11-$ $\tau / r f\left(X_{I} / X_{B}\right)^{\beta_{2}} /(1-\rho)^{2}\left(\partial \gamma_{1} / \partial \rho 1 / \gamma_{1}^{2}(1-\rho)^{2}-I / 1-\tau / r-\right.$ $\left.\mu X_{I}-\beta_{2} / \beta_{2}-11-\tau / r f\left(X_{I} / X_{B}\right)^{\beta_{2}}\right)$. In this equation, $1-\tau / r-\mu X_{I}-\beta_{2} / \beta_{2}-11-\tau / r f\left(X_{I} / X_{B}\right)^{\beta_{2}}>1-\tau / r-$ $\mu X_{I}-\beta_{2} / \beta_{2}-11-\tau / r f\left(X_{I} / X_{B}\right)=0$, whether $\partial F / \partial \rho$ is positive or negative, depending on the expression in the bracket. Denote the function $g(\rho)=\partial \gamma_{1} / \partial \rho 1 / \gamma_{1}^{2}(1-\rho)^{2}-$ $I / 1-\tau / r-\mu X_{I}-\beta_{2} / \beta_{2}-11-\tau / r f\left(X_{I} / X_{B}\right)^{\beta_{2}}$; then, $g(\rho)$ decreases with $\rho$. Since $g(1)=-I / 1-\tau / r-\mu X_{I^{-}}$ 
$\beta_{2} / \beta_{2}-11-\tau / r f\left(X_{I} / X_{B}\right)^{\beta_{2}}<0, \quad g(0)=\left(1-\tau / r-\mu \quad X_{I}-\right.$ $\left.\beta_{2} / \beta_{2}-11-\tau / r f\left(X_{I} / X_{B}\right)^{\beta_{2}}\right)\left(I^{\prime}-I\right)$; when $I>I^{\prime}, \partial F / \partial \rho>0$, so $\partial X_{I} / \partial \rho=-\partial F / \partial \rho / \partial F / \partial X_{I}>0$, namely, the investment boundary increases with the completion risk probability. When $I \leq I^{\prime}$, there exists a completion risk probability $\rho_{1}$ that satisfies $g\left(\rho_{1}\right)=0$, and when $0<\rho<\rho_{1}, \partial F / \partial \rho<0$, so $\partial X_{I} / \partial \rho=-\partial F / \partial \rho / \partial F / \partial X_{I}<0$, so the investment boundary decreases with the completion risk probability. When $\rho \geq \rho_{1}$, $\partial F / \partial \rho>0$, so $\partial X_{I} / \partial \rho=-\partial F / \partial \rho / \partial F / \partial X_{I}>0$, so the investment boundary increases with the completion risk probability. Besides, $\partial F / \partial f=-\left(1-\beta_{2} / \gamma_{1}\right) 1-\tau / r\left(X_{I} / X_{B}\right)^{\beta_{2}}+$ $1-\tau / r ;$ since $X_{I}>\left(1 / 1-\beta_{2} / \gamma_{1}\right)^{1 / \beta_{2}} X_{B}, \quad \partial F / \partial \rho>0$, so $\partial X_{I} / \partial \rho=-\partial F / \partial \rho / \partial F / \partial X_{I}>0$, so the investment boundary increases with the operating cost.

Proof of Proposition 4

$\bar{X}_{D}-\bar{X}_{B}=r-\mu / r \beta_{2} / \beta_{2}-1 C>0$ (QED).

Proof of Proposition 5

Denote the function $Q\left(\bar{X}_{I}, \cdot\right)$ as $Q\left(\bar{X}_{I}, \cdot\right)=$ $\left(1-\beta_{2} / \gamma_{1}\right) A_{1} \bar{X}_{D}^{1-\beta_{2}} \bar{X}_{I}^{\beta_{2}}+\left(1-1 / \gamma_{1}\right) 1-\tau / r-\mu \quad \bar{X}_{I}+\tau C / r-$ $(1-\tau) / r f$. It can be derived that $\partial Q / \partial \bar{X}_{I}=$ $\left(1-\beta_{2} / \gamma_{1}\right) A_{1} \beta_{2} \bar{X}_{D}^{1-\beta_{2}} \bar{X}_{I}^{\beta_{2}-1}+\left(1-1 / \gamma_{1}\right) 1-\tau / r-\mu>0$. Also, $\partial Q / \partial \rho=\beta_{2} / \gamma_{1}^{2} \partial \gamma_{1} / \partial \rho A_{1} \bar{X}_{D}^{1-\beta_{2}} \bar{X}_{I}^{\beta_{2}}+1 / \gamma_{1}^{2} \partial \gamma_{1} / \partial \rho 1-\tau / r-$ $\mu \bar{X}_{I}-I /(1-\rho)^{2}=1 /(1-\rho)^{2}\left(1 / \gamma_{1}^{2} \partial \gamma_{1} / \partial \rho(1-\rho)^{2}\left(\beta_{2} A_{1} \bar{X}_{D}^{1-}\right.\right.$ $\left.\left.\beta_{2} \bar{X}_{I}^{\beta_{2}}+1-\tau / r-\mu \bar{X}_{I}\right)-I\right)$, and denote function $g(\rho)=1 / \gamma_{1}^{2} \partial \gamma_{1} / \partial \rho(1-\rho)^{2}\left(\beta_{2} A_{1} \quad \bar{X}_{D}^{1-\beta_{2}} \bar{X}_{I}^{\beta_{2}}+1-\tau / r-\right.$ $\left.\mu \bar{X}_{I}\right)-I$; then, $g(\rho)$ decreases with $\rho$; on the other hand, $g(1)=-I<0, g(0)=I^{\prime \prime}-I$. So, when $I^{\prime \prime}<I, \partial Q / \partial \rho<0$, $\partial \bar{X}_{I} / \partial \rho=-\partial Q / \partial \rho / \partial Q / \partial \bar{X}_{I}>0$; when $I^{\prime \prime} \geq I$, there must exist $\rho_{2}$ that satisfies $g\left(\rho_{2}\right)=0$, so when $0<\rho<\rho_{2}, \partial Q / \partial \rho>0$, so $\partial \bar{X}_{I} / \partial \rho=-\partial Q / \partial \rho / \partial Q / \partial \bar{X}_{I}<0$, and when $\rho>\rho_{2}, \partial Q / \partial \rho<0$, so $\partial \bar{X}_{I} / \partial \rho=-\partial Q / \partial \rho / \partial Q / \partial \bar{X}_{I}>0$. Besides, $\partial Q / \partial \alpha=$ $-\left(1-\beta_{2} / \gamma_{1}\right) 1 / r \bar{X}_{D}^{1-\beta_{2}} \bar{X}_{I}^{\beta_{2}}<0$, so $\partial \bar{X}_{I} / \partial \alpha=-\partial Q / \partial \rho / \partial Q /$ $\partial \bar{X}_{I}>0$. Also, $\partial Q / \partial f=-\left(1-\beta_{2} / \gamma_{1}\right) r / r-\mu 1 / \beta_{2} A_{1} \bar{X}_{D}^{-\beta_{2}} \bar{X}_{I}^{\beta_{2}}-$ $1-\tau / r f<0$, so $\partial \bar{X}_{I} / \partial f=-\partial Q / \partial \rho / \partial Q / \partial \bar{X}_{I}>0$.

Proof of Proposition 6

$I^{\prime \prime}-I^{\prime}=\beta_{2} A_{1} \bar{X}_{D}^{1-\beta_{2}} \bar{X}_{I}^{\beta_{2}}+1-\tau / r-\mu\left(\bar{X}_{I}-X_{I}\right)+\beta_{2} /$

$\beta_{2}-11-\tau / r f\left(X_{I} / X_{B}\right)^{\beta_{2}} / 2 \sigma^{2}\left(\left(\left(1 / 2-\mu / \sigma^{2}\right)^{2}+r / \sigma^{2}\right)\right.$

$\sqrt{\left(1 / 2-\mu / \sigma^{2}\right)^{2}+2 r / \sigma^{2}}+\left(1 / 2-\mu / \sigma^{2}\right)\left(\left(1 / 2-\mu / \sigma^{2}\right)^{2}+2 r /\right.$ $\left.\sigma^{2}\right)$ ), and combining equations (13) and (32), it can be derived that $\beta_{2} A_{1} \bar{X}_{D}^{1-\beta_{2}} \bar{X}_{I} \quad \beta_{2}+1-\tau / r-\mu\left(\bar{X}_{I}-X_{I}\right)+$ $\beta_{2} / \beta_{2}-11-\tau / r f\left(X_{I} / X_{B}\right)^{\beta_{2}}=\left(\gamma_{1} / \gamma_{1}-\beta_{2}\right)((1-\tau / r-\mu(1-$ $\left.\left.\left.\beta_{2}\right)\left(\bar{X}_{I}-X_{I}\right)\right)-\beta_{2} \tau / r C\right)$, so when it is satisfied that $\bar{X}_{I}-X_{I}>\beta_{2} / 1-\beta_{2} \tau / 1-\tau r-\mu / r C$, i.e., when $X_{I}-\bar{X}_{I}<k C$, $k=\beta_{2} / \beta_{2}-1 \tau / 1-\tau r-\mu / r$; then, $I^{\prime}<I^{\prime \prime}$; otherwise, $I^{\prime} \geq I^{\prime \prime}$. Besides, $\rho_{1}$ and $\rho_{2}$ are the solutions to the following equations, respectively:

$$
\begin{array}{r}
\frac{\partial \gamma_{1}}{\partial \rho} \frac{1}{\gamma_{1}^{2}}(1-\rho)^{2}-\frac{I}{1-\tau / r-\mu X_{I}-\beta_{2} / \beta_{2}-11-\tau / r f\left(X_{I} / X_{B}\right)^{\beta_{2}}}=0 \\
\frac{1}{\gamma_{1}^{2}} \frac{\partial \gamma_{1}}{\partial \rho}(1-\rho)^{2}-\frac{I}{\left(\beta_{2} A_{1} \bar{X}_{D}^{1-\beta_{2}} \bar{X}_{I}^{\beta_{2}}+1-\tau / r-\mu \bar{X}_{I}\right)}=0 .
\end{array}
$$

The function $g(\rho)=\partial \gamma_{1} / \partial \rho 1 / \gamma_{1}^{2}(1-\rho)^{2}-a$ decreases with $\rho$, given that $g(\rho, a)=0$, i.e., $\gamma_{1} / \rho 1 / \gamma_{2}(1-\rho)^{2}=a$, the larger value of $a$, the smaller value of $\rho$ the larger is $a$ and the smaller is $\rho$. If $I^{\prime}<I^{\prime \prime}$, it is satisfied that $\beta_{2} A_{1} \bar{X}_{D}^{1-\beta_{2}} \bar{X}_{I}^{\beta_{2}}+$ $1-\tau / r-\mu \bar{X}_{I}>1-\tau / r-\mu X_{I}-\beta_{2} / \beta_{2}-11-\tau / r f\left(X_{I} / X_{B}\right)^{\beta_{2}}$, so $\quad I / \beta_{2} A_{1} \bar{X}_{D}^{1-\beta_{2}} \bar{X}_{I}^{\beta_{2}}+1-\tau / r-\mu \bar{X}_{I}<I / 1-\tau / r-\mu X_{I^{-}}$ $\beta_{2} / \beta_{2}-11-\tau / r f\left(X_{I} / X_{B}\right)^{\beta_{2}}$, so $\rho_{1}<\rho_{2}$; otherwise, it is satisfied that $I^{\prime} \geq I^{\prime \prime}$ and $\rho_{1} \geq \rho_{2}$.

\section{Data Availability}

The data used to support the findings of this study are included within the article.

\section{Conflicts of Interest}

The authors declare that they have no conflicts of interest.

\section{Acknowledgments}

This study was financially supported by the China Scholarship Council under grant no. 201806250070.

\section{References}

[1] W. Xiong and X. Zhang, "Concession renegotiation models for projects developed through public-private partnerships," Journal of Construction Engineering and Management, vol. 140, no. 5, Article ID 04014008, 2014.

[2] S. Zhang, Y. Gao, Z. Feng, and W. Sun, "PPP application in infrastructure development in China: institutional analysis and implications," International Journal of Project Management, vol. 33, no. 3, pp. 497-509, 2015.

[3] A. N. Chowdhury, P.-H. Chen, and R. L. K. Tiong, "Credit enhancement factors for the financing of Independent Power Producer (IPP) projects in Asia," International Journal of Project Management, vol. 33, no. 7, pp. 1576-1587, 2015.

[4] N. Mouraviev and N. K. Kakabadse, "Public-private partnership's procurement criteria: the case of managing stakeholders' value creation in Kazakhstan," Public Management Review, vol. 17, no. 6, pp. 769-790, 2015.

[5] N. Carbonara, N. Costantino, and R. Pellegrino, "Concession period for PPPs: a win-win model for a fair risk sharing," International Journal of Project Management, vol. 32, no. 7, pp. 1223-1232, 2014.

[6] Y. Ke, W. Hao, H. Ding, and Y. Wang, "Factors influencing the private involvement in urban rail public-private 
partnership projects in China," Construction Economics and Building, vol. 17, no. 1, pp. 90-106, 2017.

[7] E. E. Ameyaw, A. P. C. Chan, and D.-G. Owusu-Manu, "A survey of critical success factors for attracting private sector participation in water supply projects in developing countries," Journal of Facilities Management, vol. 15, no. 1, pp. 35-61, 2017.

[8] R. Osei-Kyei and A. P. C. Chan, "Factors attracting private sector investments in public-private partnerships in developing countries," Journal of Financial Management of Property and Construction, vol. 22, no. 1, pp. 92-111, 2017.

[9] L. E. T. Brandão and E. Saraiva, "The option value of government guarantees in infrastructure projects," Construction Management and Economics, vol. 26, no. 11, pp. 1171-1180, 2008.

[10] S. P. Ho, "Model for financial renegotiation in public-private partnership projects and its policy implications: game theoretic view," Journal of Construction Engineering and Management, vol. 132, no. 7, pp. 678-688, 2006.

[11] A. P. C. Chan, P. T. I. Lam, D. W. M. Chan, E. Cheung, and Y. Ke, "Critical Success Factors for PPPs in infrastructure developments: Chinese perspective," Journal of Construction Engineering and Management, vol. 136, no. 5, pp. 484-494, 2010.

[12] B.-G. Hwang, X. Zhao, and M. J. S. Gay, "Public private partnership projects in Singapore: factors, critical risks and preferred risk allocation from the perspective of contractors," International Journal of Project Management, vol. 31, no. 3, pp. 424-433, 2013.

[13] X.-H. Jin and G. Zhang, "Modelling optimal risk allocation in PPP projects using artificial neural networks," International Journal of Project Management, vol. 29, no. 5, pp. 591-603, 2011.

[14] Y. Li and X. Wang, "Risk assessment for public-private partnership projects: using a fuzzy analytic hierarchical process method and expert opinion in China," Journal of Risk Research, vol. 21, no. 8, pp. 952-973, 2016.

[15] J.-S. Chou, H. Ping Tserng, C. Lin, and C.-P. Yeh, "Critical factors and risk allocation for PPP Policy: comparison between HSR and general infrastructure projects," Transport Policy, vol. 22, pp. 36-48, 2012.

[16] N. Mouraviev and N. K. Kakabadse, "Risk allocation in a public-private partnership: a case study of construction and operation of kindergartens in Kazakhstan," Journal of Risk Research, vol. 17, no. 5, pp. 621-640, 2014.

[17] E. E. Ameyaw and A. P. C. Chan, "Evaluation and ranking of risk factors in public-private partnership water supply projects in developing countries using fuzzy synthetic evaluation approach," Expert Systems with Applications, vol. 42, no. 12, pp. 5102-5116, 2015.

[18] A. Park and C.-Y. Chang, "Impacts of construction events on the project equity value of the channel tunnel project," Construction Management and Economics, vol. 31, no. 3, pp. 223-237, 2013.

[19] A. P. C. Chan, P. T. I. Lam, D. W. M. Chan, E. Cheung, and Y. Ke, "Critical success factors for PPPs in infrastructure developments: Chinese perspective," Journal of Construction Engineering and Management, vol. 136, no. 5, pp. 484-494, 2010.

[20] H. W. Lee, K. Choi, and J. A. Gambatese, "Real options valuation of phased investments in commercial energy retrofits under building performance risks," Journal of Construction Engineering and Management, vol. 140, no. 6, Article ID 05014004, 2014.
[21] I. Mirzadeh and B. Birgisson, "Evaluation of highway projects under government support mechanisms based on an optionpricing framework," Journal of Construction Engineering and Management, vol. 142, no. 4, Article ID 04015094, 2015.

[22] A. Dias Jr. and P. G. Ioannou, "Debt capacity and optimal capital structure for privately financed infrastructure projects," Journal of Construction Engineering and Management, vol. 121, no. 4, pp. 404-414, 1995.

[23] J. E. Schaufelberger and I. Wipadapisut, "Alternate financing strategies for build-operate-transfer projects," Journal of Construction Engineering and Management, vol. 129, no. 2, pp. 205-213, 2003.

[24] S. Bakatjan, M. Arikan, and R. L. K. Tiong, "Optimal capital structure model for BOT power projects in Turkey," Journal of Construction Engineering and Management, vol. 129, no. 1, pp. 89-97, 2003.

[25] X. Zhang, "Financial viability analysis and capital structure optimization in privatized public infrastructure projects," Journal of Construction Engineering and Management, vol. 131, no. 6, pp. 656-668, 2005.

[26] S. Yun, S. H. Han, H. Kim, and J. H. Ock, "Capital structure optimization for build-operate-transfer (BOT) projects using a stochastic and multi-objective approach," Canadian Journal of Civil Engineering, vol. 36, no. 5, pp. 777-790, 2009.

[27] B. Chen and F. M. Liou, "Optimal capital structure of power plant projects with various bargaining powers in project negotiations," Journal of Energy Engineering, vol. 143, no. 2, Article ID 04016051, 2016.

[28] C.-Y. Chang, "A critical review of the application of TCE in the interpretation of risk allocation in PPP contracts," Construction Management and Economics, vol. 31, no. 2, pp. 99-103, 2013.

[29] E. Morellec, P. Valta, and A. Zhdanov, "Financing investment: the choice between bonds and bank loans," Management Science, vol. 61, no. 11, pp. 2580-2602, 2015.

[30] D. Hackbarth and D. C. Mauer, "Optimal priority structure, capital structure, and investment," Review of Financial Studies, vol. 25, no. 3, pp. 747-796, 2012.

[31] H. E. Leland, "Financial synergies and the optimal scope of the firm: implications for mergers, spinoffs, and structured finance," The Journal of Finance, vol. 62, no. 2, pp. 765-807, 2007.

[32] S. Li, D. Abraham, and H. Cai, "Infrastructure financing with project bond and credit default swap under public-private partnerships," International Journal of Project Management, vol. 35, no. 3, pp. 406-419, 2017.

[33] S. Sundaresan, N. Wang, and J. Yang, "Dynamic investment, capital structure, and debt overhang," Review of Corporate Finance Studies, vol. 4, no. 1, pp. 1-42, 2015.

[34] D. W. Diamond and Z. He, "A theory of debt maturity: the long and short of debt overhang," The Journal of Finance, vol. 69, no. 2, pp. 719-762, 2014.

[35] Z. He and W. Xiong, "Rollover risk and credit risk," The Journal of Finance, vol. 67, no. 2, pp. 391-430, 2012.

[36] M. Y. Chai, M. B. Y. Ng, S. Y. Tong, J. A. Lim, and J. J. Ngen, "The effect of corporate governance on the timeliness of $f$ nancial reporting: empirical evidences from Malaysian public listed companies," Doctoral Dissertation, UTAR, Petaling Jaya, Malaysia, 2017.

[37] R. Goldstein, N. Ju, and H. Leland, “An EBIT-based model of dynamic capital structure," The Journal of Business, vol. 74, no. 4, pp. 483-512, 2001. 
[38] E. Sfakianakis and M. van de Laar, "Fiscal effects and public risk in public-private partnerships," Built Environment Project and Asset Management, vol. 3, no. 2, pp. 181-198, 2013.

[39] D.-G. Owusu-Manu, D. J. Edwards, E. K. Kutin-Mensah, A. Kilby, E. Parn, and P. E. Love, "The impact of socio-political and economic environments on private sector participation in energy infrastructure delivery in Ghana," Journal of Engineering, Design and Technology, vol. 15, no. 2, pp. 166180, 2017.

[40] F. Bitsch, A. Buchner, and C. Kaserer, "Risk, return and cash flow characteristics of infrastructure fund investments," $E I B$ Papers, vol. 15, no. 1, pp. 106-136, 2010. 